\title{
Response-contingent sensory change in a causally structured environment
}

\author{
PETER H. GLOW and ANTHONY H. WINEFIELD \\ University of Adelaide, Adelaide, South Australia 5001
}

\begin{abstract}
Sensory-contingent barpressing was studied in a causally structured environment. It was found that the reinforcing effect of sensory change was enhanced when it signaled the opportunity to produce a further, different sensory change. Prior experience of different kinds of lack of control was found to influence the amount of barpressing under full control. In general, lack of control which involved ineffective responding produced decreased responding under full control, whereas lack of control which involved lack of opportunity to respond tended to increase responding under full control. The results were interpreted in accordance with three hypotheses: learned ineffectiveness, frustration, and preference shift.
\end{abstract}

Sensory reinforcement research (Kish, 1966) has typically utilized an experimental situation in which a particular sensory change is made contingent on a unit of behavior (usually a barpress in an animal experiment) and the contingency is available throughout the whole experimental session (e.g., Berlyne, 1969; Lockard, 1966). Thus, there is a one-toone relationship between a piece of behavior and an environmental change. This arrangement limits organism-environmental interaction by confining it to a single contingency for the purpose of study (cf. Hulse, 1973). Possibilities for organismenvironment interaction may be expanded by increasing the causal structure of the environment. Causal structure can be defined in terms of the extent to which an initial response-environmental change contingency makes available further and different contingencies. The typical one-to-one relationship of the sensory-contingent barpressing paradigm has a low causal structure because the contingency available does not depend on any prior and different contingency.

In the experiments described here a new paradigm was studied in which a first response-produced sensory change (light onset) of limited duration served as a discriminative stimulus for a second response-produced sensory change (sound offset). This paradigm, in which both sensory changes were contingent on responding will hereafter be referred to as CC (contingent light change, contingent sound change). It has been argued that the reinforcement in sensory-contingent barpressing arises mainly from the opportunity to control the environment (Glow,

This research was supported by a grant from the Australian Research Grants Committee. Reprints can be obtained from Dr. P. H. Glow, Department of Psychology, The University of Adelaide, G.P.O. Box 498, Adelaide, South Australia 5001.
Roberts, \& Russell, 1972; Glow \& Russell, 1972; Kavanau, 1967). Increasing the causal structure of the environment will tend to increase the extent to which the environment is under potential behavioral control. According to this argument, the reinforcement is provided not only by control of the light change per se, but also by what is added to the light change, namely the opportunity to control a further sensory change. Thus, it was predicted that the level of responding for light change would be greater if the light change was associated with the opportunity to produce a sound change. This hypothesis takes into account the fact that the light and sound changes have been shown to be equally reinforcing (Glow \& Russell, 1974a, 1974b).

There is some similarity between the CC paradigm and a two-component chain schedule in operant conditioning (Kelleher, 1966). The essential difference would seem to be that, whereas in the chain schedule the second stimulus always terminates with primary reinforcement while the first stimulus may or may not be a conditioned reinforcer, in the CC paradigm it cannot be assumed that the sound change, but not the light change, is a primary reinforcer.

The basic CC paradigm can be modified in a variety of ways. For example, either light changes or sound changes, or both, can be made to occur independently of responding (noncontingent). Moreover, noncontingent sensory changes can be programmed to occur with or without the opportunity to respond, by the use of retractable; as opposed to a fixed, lever. The effects of varying the amount of, and opportunity for, control over sensory change were studied using various modifications of the CC paradigm on both ongoing behavior and subsequent behavior with increased or reduced control.

In the first experiment a fixed lever was used, but in the later experiments a retractable lever was used. 


\section{EXPERIMENT 1}

The main purpose of this experiment was to explore the properties of the basic $\mathrm{CC}$ paradigm and to test the proposition that increased causal structure would lead to increased responding. Two subsidiary questions arising from this were also studied. One was whether animals would learn to respond for sound change during the period of light change when the light change was not under their control but instead occurred independently of responding. The other concerned the extent to which animals would learn to respond for sound change when it was made contingent on two responses within a limited period equivalent to the duration of the light change, but in its absence.

The second aim was to investigate the effects of prior experience with partial control of sensory change on subsequent sensory-contingent barpressing behavior with full control. It was reasoned that such prior experience would lead animals in different treatments to develop different expectations about the extent to which their behavior was causally related to sensory change. In one treatment, for example, responses made outside the light period were not reinforced, and hence animals should learn not to expect a one-to-one relationship between barpressing and sensory change. By contrast, in another treatment all barpressing outside the light period was reinforced with light change, and thus animals should learn an expectation that barpressing was effective in producing sensory change. In the second phase of the study, half the animals in each of three experimental treatments were switched to the fullcontrol condition. Interest centered on the level of sensory-contingent barpressing behavior as a function of prior experience.

\section{Method}

\section{Subjects}

The subjects were 80 naive female hooded Wistar rats, approximately 120 days of age. The animals were obtained from the University colony at 100 days, caged singly in air-conditioned quarters on a 12-h light-dark cycle and routinely handled. They were kept on ad-lib food and water prior to and throughout the experiment.

\footnotetext{
Apparatus

The apparatus consisted of eight sound-insulated light-tight and air-conditioned chambers containing single-lever Skinner boxes, $21.6 \times 20.3 \times 22.9 \mathrm{~cm}$, constructed from unpainted aluminum panels with a Perspex door and ceiling. Two lights (Philips $0.8 \mathrm{~V}, 0.82 \mathrm{~A}$ ) were mounted $2 \mathrm{~cm}$ below the top of the box and $5 \mathrm{~cm}$ from the sides on the wall facing the lever. A $5 \times 1.3 \mathrm{~cm}$ metal level protruded $1.3 \mathrm{~cm}$ from a wall $7.5 \mathrm{~cm}$ from the floor. Approximately $20 \mathrm{~g}$ of weight was required to operate the lever. The sensory reinforcers used were light onset, a 3-sec change from darkness to $71.58 \mathrm{~lx}$, and sound offset, a 3-sec change from $86 \pm 1 \mathrm{~dB}$ (re $0.0002 \mathrm{dyn} / \mathrm{cm}^{2}$ ) to a background level of $73 \pm 1 \mathrm{~dB}$ by the offset of a buzzer $133 \mathrm{~Hz}$. The background sound level was obtained from white noise (Grason-
}

Stadler generator). The buzzer was mounted within the soundinsulated chamber but outside the Skinner box. The ambient light intensity was measured in the vicinity of the lever by a Lunasix photometer. The sound intensities were measured in the vicinity of the lever with a Dawe sound-level indicator on scale A. Recording and control equipment was housed in a room adjacent to that containing the Skinner boxes.

\section{Procedure and Experimental Design}

The experiment involved repeated testing with a 20 -min session and a 48-h intersession interval.

The study was conducted in two phases, as described below.

Phase 1. Twenty rats were randomly assigned to each of four groups, the first of which was the control group.

Group 1 received response-contingent light onset followed by access to response-contingent sound offset (CC). A barpress during State 1 (light OFF sound $O N$ ) produced light onset which lasted $3 \mathrm{sec}$. Any response during the period of light onset (State 2) produced sound offset of $3 \mathrm{sec}$ duration (State 3). At the end of time, subjects reverted to State 1.

Group 2 received noncontingent light onset followed by access to contingent sound offset $(\mathrm{nC})$. The occurrence of light onset was not under the animal's control. Instead, these animals were yoked to subjects in Group 1 for light onset. Thus, each time the paired animal in Group 1 responded for light onset, the change also occurred for the yoked subject in Group 2. Group 2 subjects could then respond for sound offset during the light change.

In Group 3, light onset was response-contingent, but sound offset was noncontingent $(\mathrm{Cn})$. Barpressing produced light onset, but responses made during the light change produced no sensory change. Subjects in Group 3 were yoked to those in Group 1 for sound offset.

In Group 4, animals were required to make two responses within $3 \mathrm{sec}$ to obtain sound offset (.C). The first of the two responses in the $3 \mathrm{sec}$ did not produce a sensory change. For all groups, responses during sound offset (State 3 ) were recorded but did not affect the situation.

Phase 1 lasted for 18 sessions. Total number of responses (i.e., State $1+$ State $2+$ State 3 ) and the numbers of responses in each of the three states were recorded.

Phase 2. In Phase 2, each of the four groups was divided into two subgroups, matched with respect to responses in Phase 1. The eight groups are designated in accordance with the Phase 1 and Phase 2 treatments received, as shown in Table 1. Groups 21, 31 , and 41 were thus all provided with increased opportunities to respond for sensory change, while the reverse occurred in Group 13. Groups 11, 21, 31, and 41 were all responding under

Table 1

Experiment 1: Summary of Experimental Treatments in Each Phase

\begin{tabular}{|c|c|c|c|}
\hline \multicolumn{2}{|c|}{ Phase 1} & \multicolumn{2}{|c|}{ Phases 1 and 2} \\
\hline Group & Treatment & Group & Treatment \\
\hline 1 & $\mathrm{CC}$ & $\begin{array}{l}11 \\
13\end{array}$ & $\begin{array}{l}\mathrm{CC} / \mathrm{CC} \\
\mathrm{CC} / \mathrm{Cn}\end{array}$ \\
\hline 2 & $\mathrm{nC}$ & $\begin{array}{l}22 \\
21\end{array}$ & $\begin{array}{l}\mathrm{nC} / \mathrm{nC} \\
\mathrm{nC} / \mathrm{CC}\end{array}$ \\
\hline 3 & $\mathrm{Cn}$ & $\begin{array}{l}33 \\
31\end{array}$ & $\begin{array}{l}\mathrm{Cn} / \mathrm{Cn} \\
\mathrm{Cn} / \mathrm{CC}\end{array}$ \\
\hline 4 &. $\mathrm{C}$ & $\begin{array}{l}44 \\
41\end{array}$ & $\begin{array}{l}. \mathrm{C} / \mathrm{C} \\
. \mathrm{C} / \mathrm{CC}\end{array}$ \\
\hline
\end{tabular}

Note-Treatment 1: contingent light, contingent sound; $C C$. Treatment 2: noncontingent light, contingent sound; $n C$. Treatment 3: contingent light, noncontingent sound; $\mathrm{Cn}$. Treatment 4: contingent sound; .C. 
$\mathrm{CC}$ in Phase 2 but had different prior experiences of contingent and noncontingent sensory change.

Phase 2 ran for 15 sessions, and responses in each of the three states were recorded.

\section{Phase 1}

\section{Results}

The acquisition data are shown in Figure 1, where fitted regression curves are presented. Clearly, only Group 4 showed any marked change over sessions, (State 2 or total responses). There was an overall difference between the groups with respect to total responses $[F(3,76)=12.57, p<.01]$, State 1 responses $[\mathrm{F}(3,76)=82.85, \mathrm{p}<.001]$, and State 3 responses $[F(3,76)=10.20, p<.01]$. Individual planned comparisons between Groups 1 and 3 revealed significant differences on all three measures at the $5 \%$ level. The respective means were 41.1 and 29.4 (for total responses), 30.3 and 23.6 (for State 1 responses), and 8.14 and 5.57 (for State 2 responses).

Although receiving almost no sound reinforcements during the first four sessions, Group 4 eventually maintained a level of responding that produced more sound changes than any other group. Over the final six sessions of Phase 1, animals in this group were averaging over 40 barpresses per session, for about 12 sound changes per session. This total number of barpresses was not significantly different from the total number of barpresses per session in Group 1. But, whereas the latter group was receiving light onset for its "first" response, animals in Group 4 received no sensory change for the compar- able response. This suggests that sound offset alone is a highly effective sensory reinforcer.

Another way of looking at barpressing in Group 4 is to consider the two barpresses within $3 \mathrm{sec}$ as a unit of behavior needed to obtain sound offset. The first response provided the animal with an opportunity to produce a sound change (by making a further response with $3 \mathrm{sec}$ ). The same applied of course in Group 1, except that there the first response also produced a light change, which in turn could serve as a signal. In fact, the level of State 1 responding was similar for the two groups (27.93 for Group 1, 29.55 for Group 4) and Group 4 subjects produced more State 3 responses (13.42 vs. 8.03). This difference exceeded the critical least significant difference $^{1}$ (Duncan, 1955) for the 5\% level of significance on each of the last six sessions of Phase 1.

\section{Phase 2}

Responding in Phase 2 varied across sessions in those groups which had had the reinforcement conditions switched to $\mathrm{CC}$. To assess the effects of the new reinforcement conditions in comparison with their matched treatment groups of Phase 1, analyses were conducted only on the last five sessions of Phase 2, by which time responding was stable. The data have been summarized in Figure 2.

In comparison with their respective matched groups, Group 31 increased its total number of responses significantly in Phase $2[\mathrm{t}(18)=3.45$, $\mathrm{p}<.01$ ], and Group 13 decreased its total number of
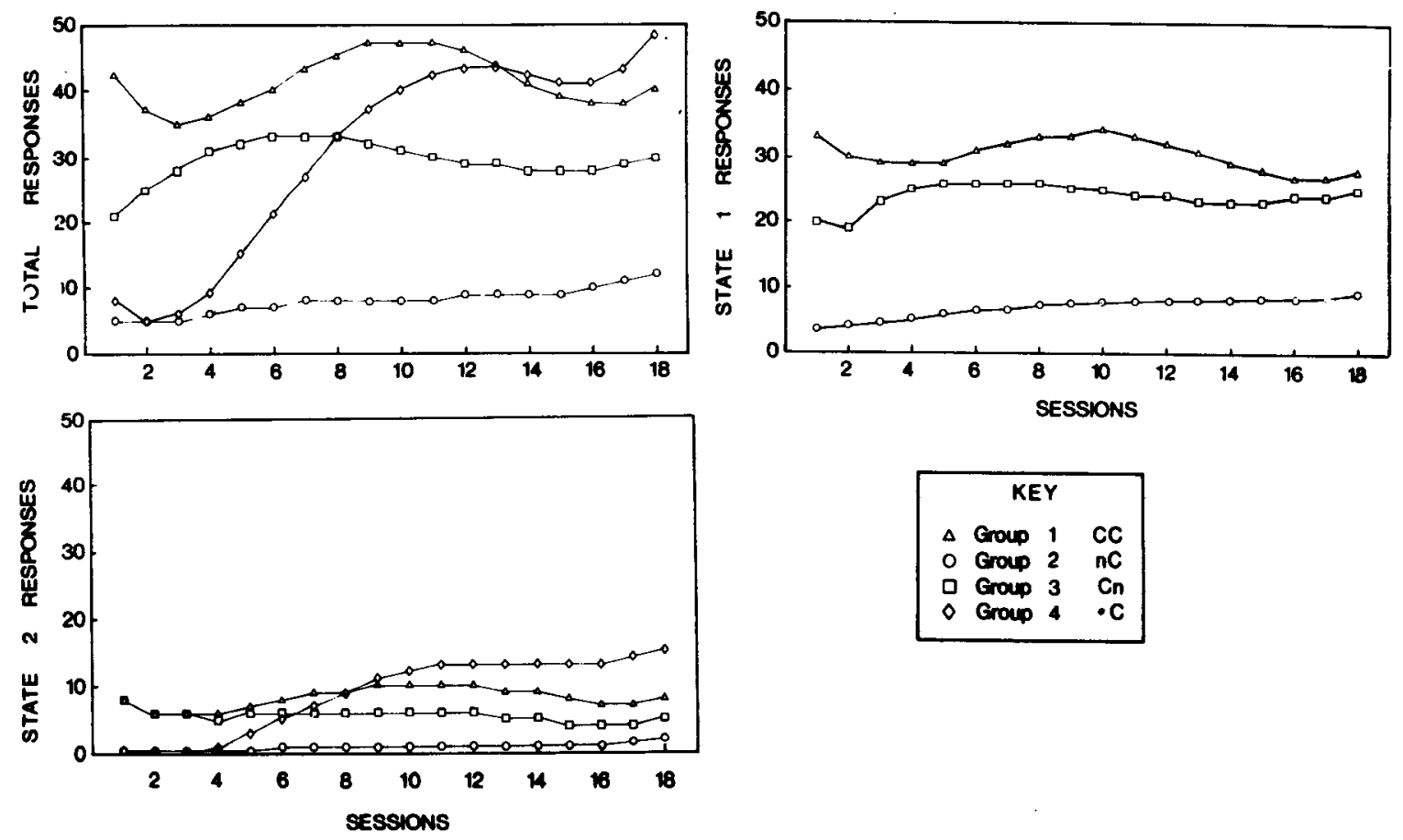

Figure 1. Experiment 1 Phase 1, fitted acquisition curves. 

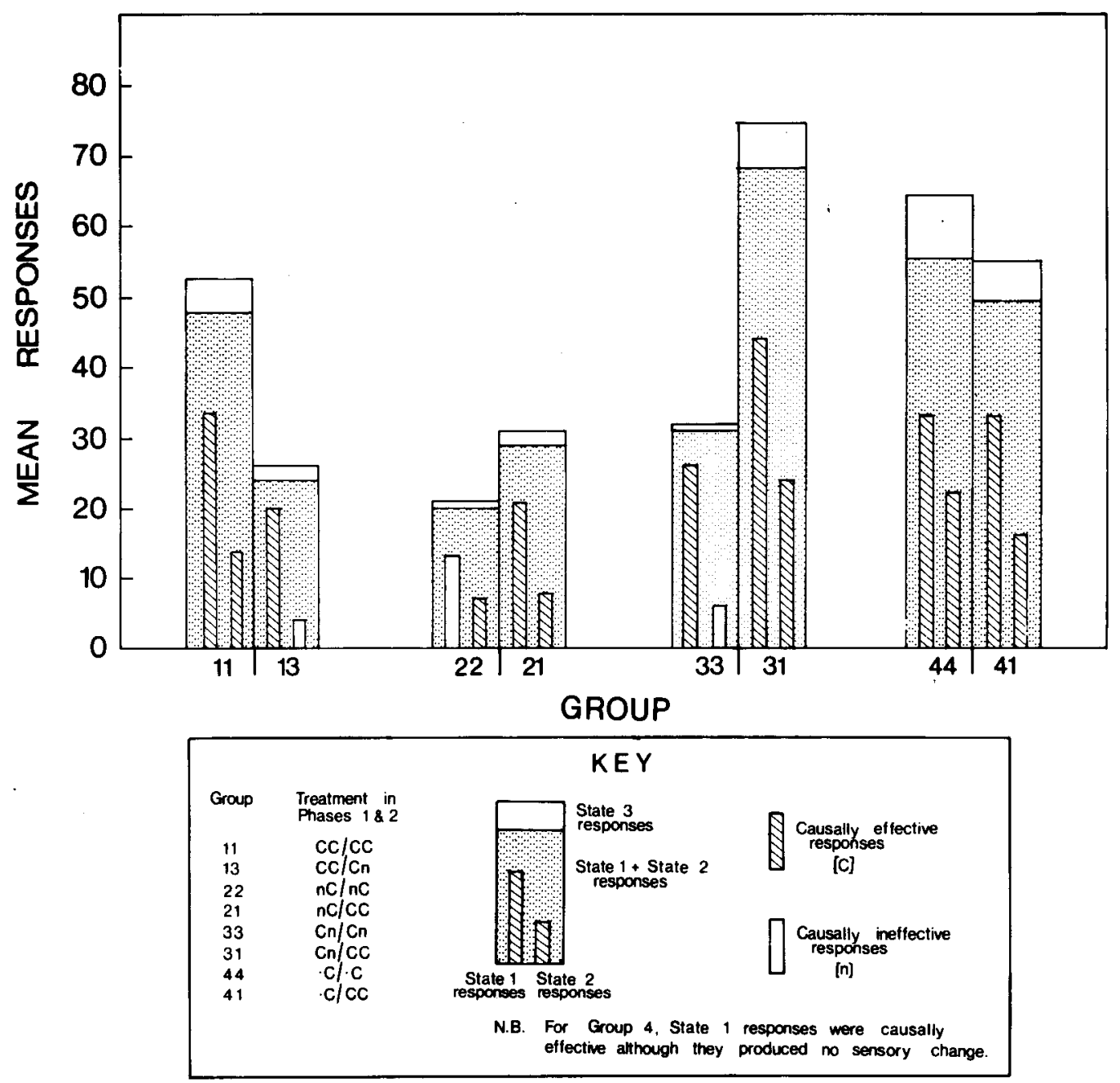

Figure 2. Experiment 1 Phase 2, mean responses over last five sessions.

responses $[\mathrm{t}(18)=2.39, \mathrm{p}<.05]$. This supports the findings from the Phase 1 analysis that $\mathrm{CC}$ was more reinforcing than $\mathrm{Cn}$. In fact, there was slightly fewer total barpresses in Group 41 than in Group 44. Thus, increasing the reinforcement by giving light onset for the "first" barpress (Group 41) actually resulted in less barpressing than when the "first" response was not reinforced by a sensory change. The comparison of Groups 11 and 13 showed a significant decrease in responding with the deletion of the sound offset as a response-contingent change. Thus, deleting a response-contingent change significantly reduced barpressing (Group 11 vs. 13), while adding a response-contingent change increased the total level of barpressing (Group 33 vs. 31) in one case, but had no significant effect in Groups 44 and 41 and Groups 22 and 21.

Further analyses were then carried out on State 1 and State 2 responding. These analyses showed that in the case of Groups 11 and 13 there was a signifi- cant difference in State 2 responding $[\mathrm{t}(18)=2.43$, $\mathrm{p}<.05]$, but not for State 1 responding $[\mathrm{t}(18)=$ $1.67, .05<\mathrm{p}<.1$ ]. For Groups 22 and 21 , there was no difference in State 2 responding $[\mathrm{t}(18)<1]$ but there was a significant difference in State 1 responding $[t(18)=2.14, p<.05]$. The comparison of Groups 33 and 31 showed a significant difference in both State $2[\mathrm{t}(18)=3.94, \mathrm{p}<.01]$ and State 1 responding $[t(18)=2.08, p<.05]$. For Groups 44 and 41 , there was no significant difference in either State 1 responding $[t(18)<1]$ or in State 2 responding $[\mathrm{t}(18)<1]$.

The second part of the Phase 2 analysis compared the four groups $(11,21,31$, and 41$)$, all responding for $\mathrm{CC}$. Responding in these groups differed significantly $[F(3,36)=2.94, p<.05]$, showing that different past experiences significantly affected the level of sensory-contingent barpressing behavior. Moreover, these groups also differed significantly with respect to State 1 responding $[F(3,36)=3.19$, 
$\mathrm{p}<.05$ ] although not with respect to State 2 responding $[F(3,36)=2.50, p>.05]$. Post hoc comparisons showed that only the difference between Groups 21 and 31 was statistically significant.

\section{Discussion}

In Phase 1, we investigated the effect on sensorycontingent barpressing behavior of manipulating the causal structure of the environment with naive animals in a fixed-lever situation. In Group 1 (treatment $\mathrm{CC}$ ), the causal structure of the environment was increased beyond the typical situation involving a single response-sensory change contingency. The effect of different causal structures can be assessed by comparing Groups 1 and 3 (treatment $\mathrm{Cn}$ ). The total number of responses in Group 1 was significantly above that in Group 3. It might be claimed that this was due to Group 1's having a response during light change (State 2) reinforced whereas in Group 3 a comparable response was not reinforced. However, the amount of State 1 responding as well as the amount of State 2 responding was significantly greater for Group 1 , which supports the hypothesis that additional opportunity for control of the environment was an effective reinforcer.

The reinforcing effect of the added control provided by the opportunity to respond for sound offset in the $\mathrm{CC}$ treatment can also be assessed from the Phase 2 data. Group 31 had the opportunity to respond for sound offset added to the light onset reinforcement in Phase 2, and showed a significant increase in State 1 responding. By contrast, Group 13 had the opportunity to respond for sound offset deleted from the light onset period. It would be consistent with the present hypothesis to predict that this would reduce the reinforcing value of response-contingent light onset. As Figure 2 shows, State 1 tesponding did decline, but not significantly. In general, the present findings provide overall support for the hypothesis that an increase in the causal structure of the environment increases the reward value of response-produced sensory change.

The second question arising from both Phase 1 and Phase 2 results concerned the animal's ability to learn to respond for sound offset during the 3-sec period of availability. The relevant treatments need to be looked at individually. The data from Group 22 (treatment $\mathrm{nC} / \mathrm{nC}$ ) during the last five sessions of Phase 2 indicate that animals learned to respond during the 3-sec noncontingent light change to obtain sound offset. This finding extends to a much more difficult discrimination task: the reported capacity of rats to learn to respond for sound offset during a regular and cued $2 \frac{1}{2} 2$-min period (Glow, Russell, \& Duckmanton, 1973). It demonstrates that response-contingent sensory change can be a powerful shaper of behavior.
Even more impressive was the high level of responding shown in Group 44 (treatment .C/.C). State 1 responses for this group were reinforced solely by a 3-sec opportunity to produce a sound change. Nevertheless the level of State 1 responding was as high as for Group $11(\mathrm{CC} / \mathrm{CC})$ and the level of State 2 responding was higher. This provides convincing evidence that the opportunity to produce a sensory change can be as reinforcing as a sensory change per se. It suggests the possibility that the reinforcing properties of response-produced sensory change arise from the ability to control the environment rather than from sensory change itself. The higher level of State 2 responding suggests the further possibility that sound changes were more reinforcing when they were the only sensory changes to occur.

The effect of prior sensory-contingent barpressing experience is clearly seen when the four groups responding for CC in Phase 2 are examined. The highest level of total responding occurred in Group 31, which had the prior experience of $\mathrm{Cn}$, while the lowest level of responding occurred in Group 21, which had the prior experience of $\mathrm{nC}$. The prior experience of these two groups was comparable in that both experienced one or the other sensory change as a noncontingent event. They differed in that responses in the $\mathrm{Cn}$ treatment were usually reinforced, whereas in the $\mathrm{nC}$ treatment only those responses made during the noncontingent light change (State 2) were reinforced. The majority of responses in the $\mathrm{nC}$ treatment during Phase 1 were made outside the light change period. It would seem that the crucial difference in the prior experience of Groups 31 and 21 was that the former learned to expect that responding usually had an effect on the environment, while the latter learned to expect that responding usually had no effect on that environment. This could be said to have been training an "internal" as opposed to an "external locus of reinforcement" (Hiroto, 1974; Lefcourt, 1972; Rotter, 1966). Looked at in another way, this dichotomy could be described as the animal learning that its behavior is either effective (White, 1959) or substantially ineffective in producing sensory change. The experience in the $\mathrm{nC}$ treatment might thus be characterized as one of learned ineffectiveness, a notion which closely parallels the "learned helplessness" concept (Maier \& Seligman, 1976).

\section{EXPERIMENT 2}

Experiment 2 examined further modifications of the CC paradigm, using a retractable, rather than a fixed, lever. The retractable lever has two advantages over the fixed lever. First, it enables the experimenter to eliminate undesirable responses, e.g., holding 
the lever down. Second, it permits the comparison of two kinds of lack of control: causally ineffective responding (lever IN) vs. no opportunity to respond (lcver OUT). However, it has to be recognized that lever retraction itself is a sensory change and could well have reinforcing properties of its own.

In this study, the full-control condition was compared with various conditions in which no control was permitted, i.e., where both light and sound changes were independent of responding (noncontingent). The experiment was also concerned with the effects of decreasing, as well as increasing, the amount of control. It involved four phases, with all experimental treatments being given full control in the final phase.

The main interest of the study concerned the performance of the various groups during the final (full control) phase of the experiment. Following Seligman (1975), it was hypothesized that prior experience in a situation where environmental events occurred independently of responding (i.e., lever IN), would produce a lowering of motivation ("learned ineffectiveness" or "learned helplessness") which would manifest itself by decreased responding when events were later made response contingent. On the other hand, it was thought that lack of opportunity for control (i.e., lever OUT) would not have the same effect.

\section{Subjects \\ The subjects were 80 naive female hooded Wistar rats, approxi- mately 120 days of age. They were maintained under the same conditions as the subjects in Experiment 1.}

\section{Apparatus}

The apparatus was identical to that used in Experiment 1 .

\section{Procedure and Experimental Design}

The experiment involved repeated testing with a 20 -min session and a 48-h intersession interval. The study was conducted in four phases; the experimental conditions in each are summarized in Table 2.

Phase 1. Twenty rats were randomly assigned to each of four groups.

Group 1 received response-contingent light onset followed by access to response-contingent sound offset, CC. A barpress during State 1 (light OFF, sound ON, lever IN) produced light onset which lasted $3 \mathrm{sec}$ and lever retraction which lasted $0.5 \mathrm{sec}$ (State 2). Any response made during the last $2.5 \mathrm{sec}$ of light onset (State 3) produced sound offset and lever retraction, both of which lasted for $3 \mathrm{sec}$ (State 4). At the end of this time, the lever returned and sound onset recommenced, i.e., the animal was again in State 1. If the animal did not respond in State 3, State 4 was bypassed and the animal returned to State 1 .

Group 2 received noncontingent light onset with access to the lever, followed by noncontingent sound offset with access to the lever, nn. For subjects in this group, light and sound changes were produced by means of a yoking procedure in which the subjects in Group 1 were responsible for the sensory changes which occurred in Group 2.

Group 3 received noncontingent light onset without access to the level, followed by noncontingent sound offset with access to the lever, (n)n. As in the Group 2, the sensory changes were produced by the Group 1 subjects via a yoking procedure.

Group 4 involved noncontingent light onset without access to the lever, followed by noncontingent sound of fset with access to the lever in State 2 (a control condition for lever movement), followed in turn by noncontingent sound offset without access to the lever (n)-(n). As with Groups 2 and 3, the sensory changes were produced by the Group 1 subjects via a yoking procedure.

Phase 1 lasted for 16 sessions. Each session lasted for $20 \mathrm{~min}$ with a 48-h intersession interval. All responses made in States 1, 2 , and 3 were recorded.

Phase 2-4. In the later phases of the experiment, the subjects in each of the four groups were divided into two equal subgroups, matched with respect to the total number of response made over the last six sessions of Phase 1. The eight groups thus formed are designated in accordance with the treatments administered in each phase, as shown in Table 2. Phase 2, 3, and 4 lasted for 14, 10, and 4 sessions, respectively.

\section{Phase 1 \\ Results}

The acquisition data for Phase 1 are presented in Figure 3, which shows fitted regression curves.

Group 1 (CC) showed a clear increase on all three

Table 2

Experiment 2: Summary of Experimental Treatments in Each Phase

\begin{tabular}{|c|c|c|c|c|c|c|c|}
\hline \multicolumn{2}{|c|}{ Phase 1} & \multicolumn{2}{|r|}{ Phase 2} & \multicolumn{2}{|r|}{ Phase 3} & \multicolumn{2}{|r|}{ Phase 4} \\
\hline Group & Treatment & Group & Treatment & Group & Treatment & Group & Treatment \\
\hline 1 & $\mathrm{CC}$ & $\begin{array}{l}11 \\
15\end{array}$ & $\begin{array}{l}\mathrm{CC} / \mathrm{CC} \\
\mathrm{CC} / \mathrm{C}(\mathrm{n})\end{array}$ & $\begin{array}{l}112 \\
156\end{array}$ & $\begin{array}{l}\mathrm{CC} / \mathrm{CC} / \mathrm{nn} \\
\mathrm{CC} / \mathrm{Cn} / \mathrm{n}(\mathrm{n})\end{array}$ & $\begin{array}{l}1121 \\
1561\end{array}$ & $\begin{array}{l}\mathrm{CC} / \mathrm{CC} / \mathrm{nn} / \mathrm{CC} \\
\mathrm{CC} / \mathrm{C}(\mathrm{n}) / \mathrm{n}(\mathrm{n}) / \mathrm{CC}\end{array}$ \\
\hline 2 & $\mathrm{nn}$ & $\begin{array}{l}22 \\
21\end{array}$ & $\begin{array}{l}\mathrm{nn} / \mathrm{nn} \\
\mathrm{nn} / \mathrm{CC}\end{array}$ & $\begin{array}{l}221 \\
216\end{array}$ & $\begin{array}{l}\mathrm{nn} / \mathrm{nn} / \mathrm{CC} \\
\mathrm{nn} / \mathrm{CC} / \mathrm{n}(\mathrm{n})\end{array}$ & $\begin{array}{l}2211 \\
2161\end{array}$ & $\begin{array}{l}\mathrm{nn} / \mathrm{nn} / \mathrm{CC} / \mathrm{CC} \\
\mathrm{nn} / \mathrm{CC} / \mathrm{n}(\mathrm{n}) / \mathrm{CC}\end{array}$ \\
\hline 3 & (n)n & $\begin{array}{l}33 \\
31\end{array}$ & $\begin{array}{l}(\mathrm{n}) \mathrm{n} /(\mathrm{n}) \mathrm{n} \\
(\mathrm{n}) \mathrm{n} / \mathrm{CC}\end{array}$ & $\begin{array}{l}331 \\
316\end{array}$ & $\begin{array}{l}(\mathrm{n}) \mathrm{n} /(\mathrm{n}) \mathrm{n} / \mathrm{CC} \\
(\mathrm{n}) \mathrm{n} / \mathrm{CC} / \mathrm{n}(\mathrm{n})\end{array}$ & $\begin{array}{l}3311 \\
3161\end{array}$ & $\begin{array}{l}\text { (n)n/(n)n/CC/CC } \\
(n) n / C C / n(n) / C C\end{array}$ \\
\hline 4 & $(n)-(n)$ & $\begin{array}{l}44 \\
41 \\
\end{array}$ & $\begin{array}{l}(n)-(n) /(n)-(n) \\
(n)-(n) / C C\end{array}$ & $\begin{array}{l}441 \\
416 \\
\end{array}$ & $\begin{array}{l}(n)-(n) /(n)-(n) / C C \\
(n)-(n) / C C / n(n)\end{array}$ & $\begin{array}{l}4411 \\
4161 \\
\end{array}$ & $\begin{array}{l}(\mathrm{n})-(\mathrm{n}) /(\mathrm{n})-(\mathrm{n}) / \mathrm{CC} / \mathrm{CC} \\
(\mathrm{n})-(\mathrm{n}) / \mathrm{CC} / \mathrm{n}(\mathrm{n}) / \mathrm{CC}\end{array}$ \\
\hline
\end{tabular}

Note-CC = contingent light, contingent sound; $n n=$ noncontingent light (lever $I N)$, noncontingent sound (lever $I N) ;(n) n=$ noncontingent light (lever OUT), noncontingent sound (lever IN); $(n)-(n)=$ noncontingent light (lever OUT), lever presentation, noncontingent sound (lever OUT); $C(n)=$ contingent light, noncontingent sound (lever $O U T$ ); $n(n)=$ noncontingent light (lever IN), noncontingent sound (lever OUT). 

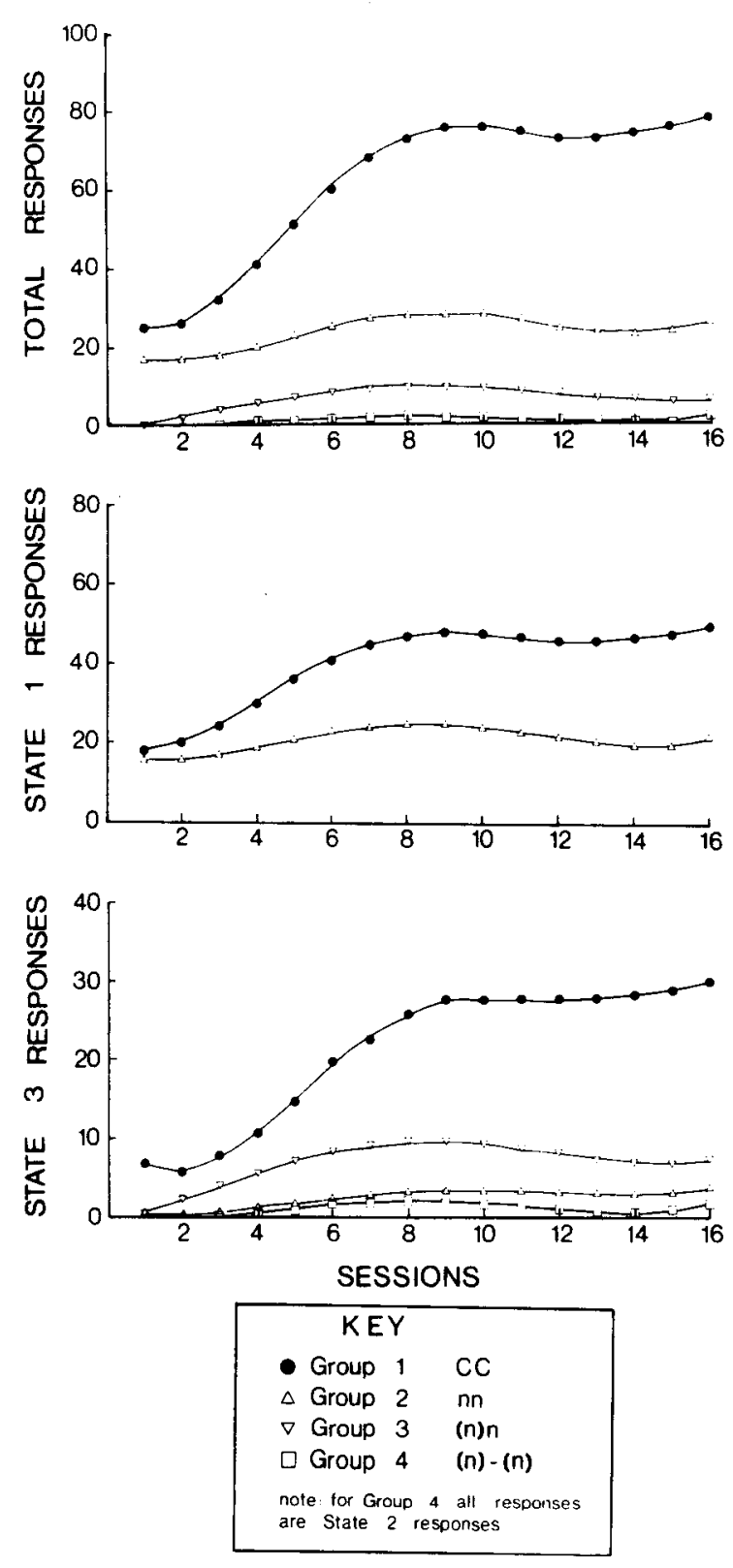

Figure 3. Experiment 2 Phase 1, fitted acquisition curves.

responses measures, unlike the corresponding Group 1 in Experiment 1. This difference must be attributed to the procedural difference of using a retractable, rather than a fixed, lever.

Analyses were carried out on the terminal six sessions over which performance was asymptotic.

For total responses, the effect of treatments was significant $[\mathrm{F}(3,76)=84.14, \mathrm{p}<.01]$. Post hoc comparisons showed that the differences between each group and each of the others were significant at the $5 \%$ level. For responses in State 1, the difference between Groups 1 and 2 was significant [t(38) $=4.43, \mathrm{p}<.01]$; and for responses in State 3 , the effect of treatments, was significant $[F(3,57)=$
$27.79, p<.01]$. The difference between Group 1 and Groups 2 and 3 were both significant, but Groups 2 and 3 did not differ significantly (post hoc tests).

\section{Phase 2}

Mean responses for the eight groups over the terminal six sessions are shown in Figure 4.

There were no significant differences among the four groups that received treatment on CC (Groups 11, 21,31 , and 41) with respect to total responding, State 1 responding, or State 3 responding.

On the other hand, when the ratios of State 3 to State 1 responses were analyzed, a significant difference was found among the four groups $[F(3,36)=$ $3.09, \mathrm{p}<.05]$. Post hoc tests showed that Group 31 was significantly different from both Groups 21 and 41 and that Group 11 was significantly different from Group 41. This measure reflects the extent to which subjects exploited opportunities to produce a sound change. Figure 4 shows that Group 31 subjects were the most efficient in this respect and that Group 41 subjects were the least efficient.

Further comparisons were made, where meaningful, between response made in States 1 and 3 for Groups 11, 22, and 33 and their respective matched Groups 15, 21, and 31. Because responding was so restricted for Group 44, no meaningful comparisons could be made with Group 41.

State 1 responding was slightly higher for Group 15 than for Group 11, but the difference was not significant $[t(18)<1]$. Group 21 showed a significantly higher level of responding than Group 22 in both State $1[\mathrm{t}(18)=2.77, \mathrm{p}<.01]$ and in State $3[\mathrm{t}(18)$ $=5.12, \mathrm{p}<.01]$. Group 31 showed a significantly higher level of responding than Group 33 in State 3 $[\mathrm{t}(18)=3.06, \mathrm{p}<.01]$.

Of the two groups that could respond ineffectively in State 3, Group 33 produced significantly more State 3 responses than did Group $22[\mathrm{t}(18)=8.80$, $\mathrm{p}<.001]$.

Overall, responding was significantly greater whenever it produced a sensory change.

\section{Phase 3}

Mean responses over the terminal six sessions are shown in Figure 5.

The main interest of the Phase 3 analysis lies in the comparison of Groups 221, 331, and 441, which were all given $\mathrm{CC}$ in this phase. For total responses, the difference among the groups was significant $[F(2,27)$ $=7.42, \mathrm{p}<.01$ ]; for responses in State 1 , the difference was significant $[F(2,27)=5.81, p<.01]$, and for responses in State 3 also, the difference was significant $[\mathrm{F}(2,27)=11.13, \mathrm{p}<.01]$. On all three measures, post hoc comparisons showed that all of the differences between individual group means were significant. None of the sessions effects nor the 

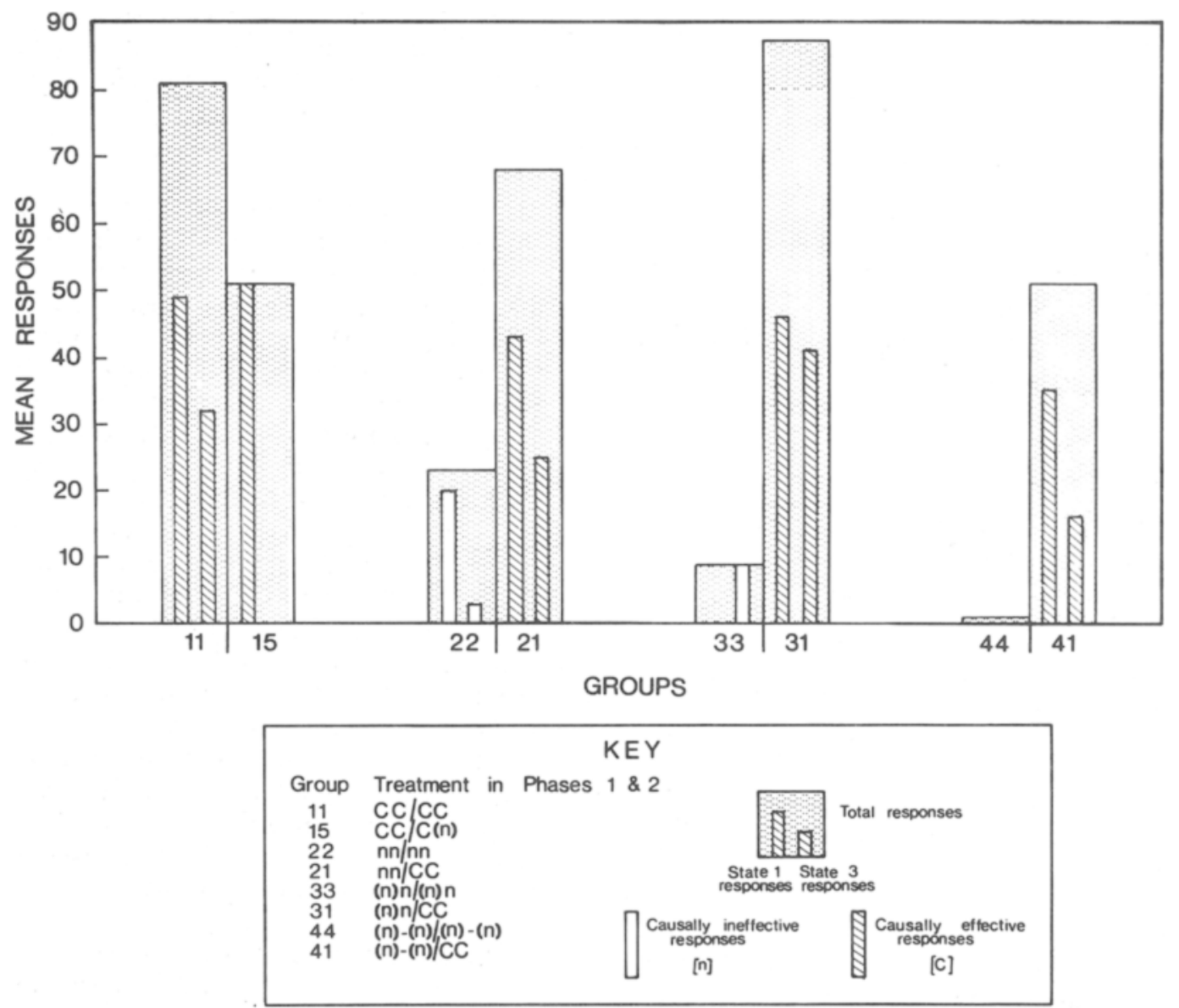

Figure 4. Experiment 2 Phase 2, mean responses over last six sessions.

Treatments by Sessions interactions were significant.

Figure 5 shows that the reason for the differences was the very high level of responding by Group 331 subjects compared with the very low level of responding by Grcup 441 subjects in both States 1 and 3 . An analysis made on the ratios of State 3 to State 1 responses also showed a significant difference between Groups 221, 331, and $441[\mathrm{~F}(2,27)=12.59$, $\mathrm{p}<.011$. Post hoc tests showed that Group 441 differed significantly from both Group 221 and Group 331. As can be seen from Figure 5, Group 441 subjects exploited only around $30 \%$ of their opportunities to produce sound changes, compared with nearly $60 \%$ for Group 221 and nearly $70 \%$ for Group 331.

As in Phase 2, responding was significantly greater whenever it produced a sensory change.

\section{Phase 4}

Mean responses during Phase 4 are shown in Figure 6.

Figure 6 shows that the level of responding in Phase 4 was strongly influenced by the Phase 1 treatment. Except for Groups 1121 and 1561, the level of responding was very similar for the groups that received the same treatment in Phase 1 (2211 and 2161,3311 and 3161 , and 4411 and 4161). For this reason, the eight groups were collapsed to four for the analysis of responses in Phase 4 (1121+ $1561,2211+2161,3311+3161,4411+4161)$. The four groups are the same as the original four in Phase 1, and for simplicity will be referred to as Groups 1-4.

For the total responses, the effect of treatments was significant $[\mathrm{F}(3,76)=7.11, \mathrm{p}<.01]$, as it was for State 1 responses $[F(3,76)=6.42, p<.01]$. For both measures, post hoc tests revealed that both Group 1 and Group 3 differed significantly from Groups 2 and 4. For State 3 responses, there was a significant effect of treatments $[\mathrm{F}(3,76)=7.54$, $\mathrm{p}<.01]$. However, for State 3 responding, post hoc tests showed that Group 3 differed significantly from both Group 2 and Group 4 but that Group 1 differed significantly only from Group 4 . In none of the analyses was the sessions effect or the Sessions by Treatments interaction significant. 


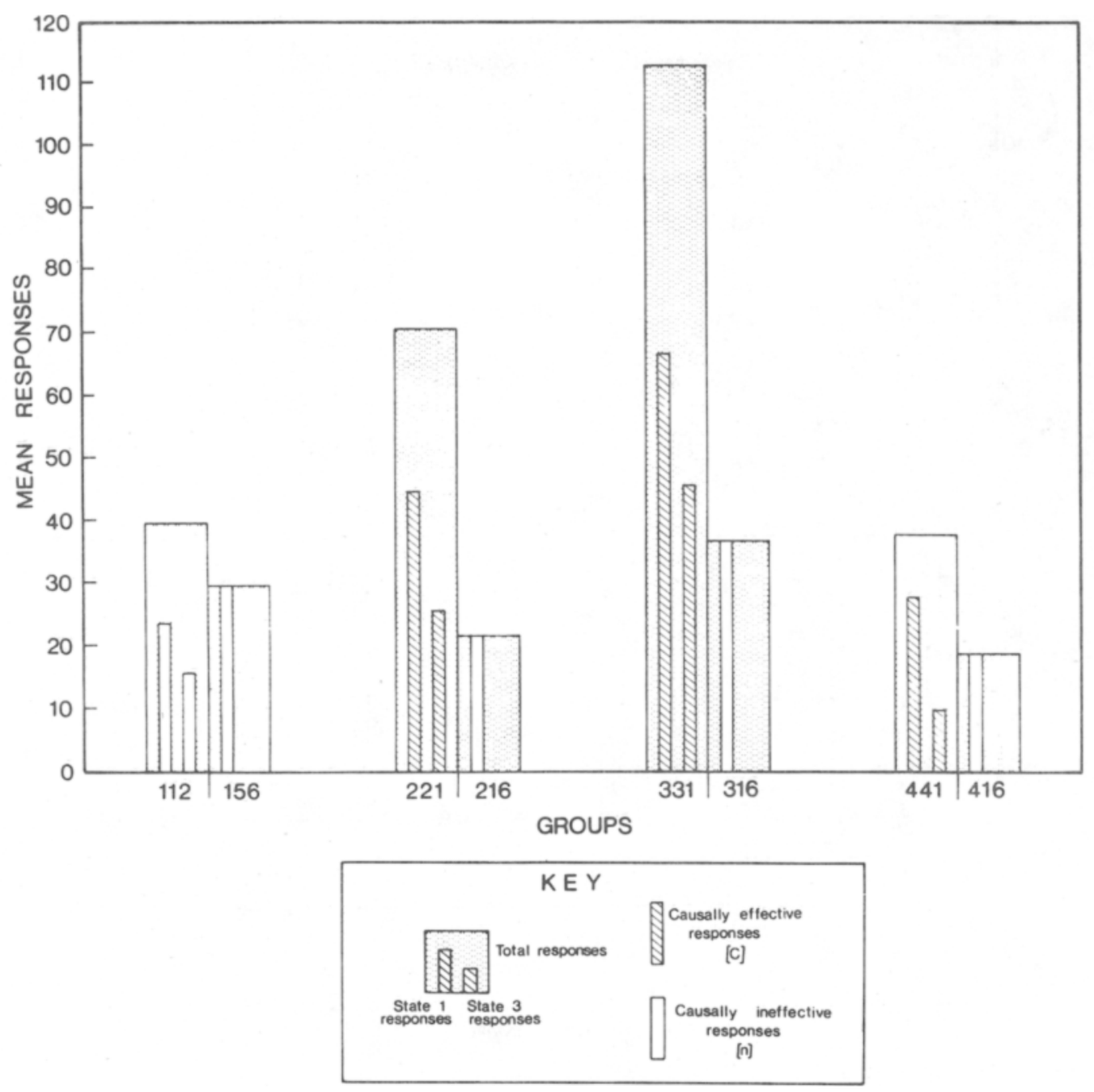

Figure 5. Experiment 2 Phase 3, mean responses over last six sessions.

Analysis of the proportion of opportunities to produce a sound change which were taken up (State 3/State 1 responses) by the various (collapsed) groups revealed a significant difference between them $[F(3,76)=8.10, p<.01]$. Post hoc tests showed that Group $3(61 \%)$ differed significantly from both Group $2(47 \%)$ and Group $4(34 \%)$, and that Group 4 differed significantly from both Group $1(56 \%)$ and Group 2.

There was a significant correlation between the rankings of the groups on this variable and total responses $($ rho $=.89, \mathrm{p}<.01)$.

\section{Discussion}

The results of this experiment confirmed once again the powerful effect that control over sensory change exerts on behavior. Throughout every phase of the experiment, sensory changes which were con- tingent on a response produced higher levels of responding than noncontingent sensory changes.

\section{Impaired Performance Following Lack of Control}

The main purpose of the study was to investigate the effects of different forms of lack of control on subsequent behavior when full control, $\mathrm{CC}$, was achieved. The behavior of the various groups in Phase 4 demonstrated the lasting effect of prior experience of lack of control. In particular, the first condition experienced by subjects seemd to be of critical importance. Groups that were identical in Phase 1 behaved very similarly in Phase 4 irrespective of different conditions that intervened. Although one of the experimental arrangements involving lack of control clearly led to a reduced level of responding when full control was achieved, as well as reduced efficiency (measured by the proportion of sound 


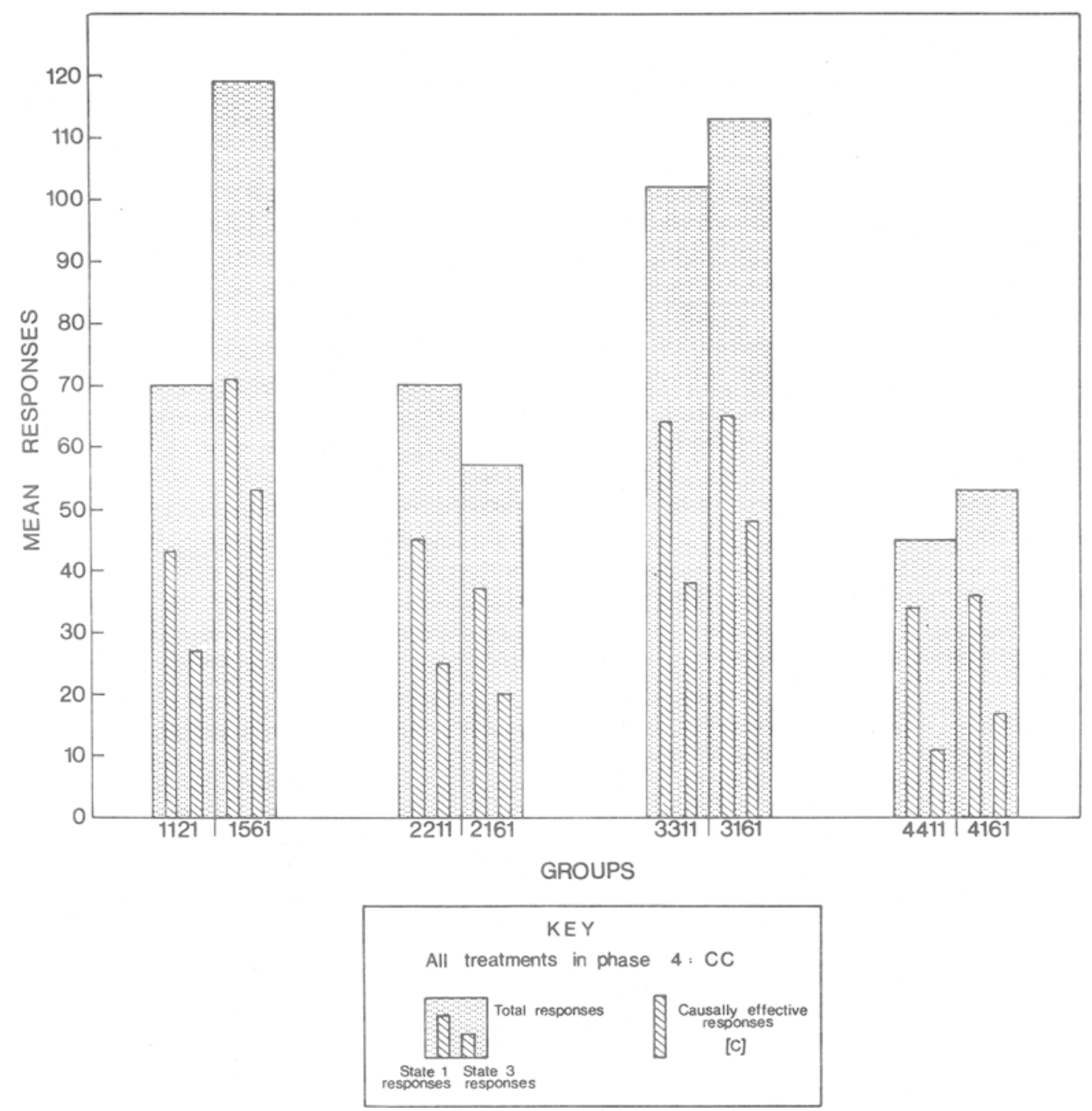

Figure 6. Experiment 2 Phase 4, mean responses.

change opportunities that were exploited), the other two had no such effects. The no-control condition with the lever absent in States 1 and 3, (n)-(n), was the one which led to subsequent impaired performance with full control, CC. On the other hand, no such effect resulted from the no-control conditions where the lever was present in States 1 and 3, $\mathrm{nn}$, and where it was absent in State 1 but present in State 3, (n)n.

A possible explanation for this anomalous finding is that the $(n) n$ condition might have created the impression of control. Under this condition, any barpress would have been followed by a sensory change (light offset) after an average of $1.5 \mathrm{sec}$ ( $2.5 \mathrm{sec}$ at most), and sometimes by two sensory changes (light of fset and sound onset). Consequently, it would not be surprising to find what might be called a "superstitious" learning effect. If this explanation is valid, we should expect to find that the level of State 3 responding was higher under the (n)n condition than under the nn condition. In fact, this was so in both Phases 1 and Phase 2 of the experiment where these conditions were presented. Figures 3 and 4 show that in Phases 1 and 2 the level of State 3 responding was higher for (n)n than for nn. In Phase 2, although not in Phase 1 , the difference was highly significant.

\section{Enhanced Performance Following Lack of Control}

So far, we have discussed only the experimental conditions which led to impaired performance when full control was achieved, but this ignores the unanticipated finding that in several cases enhanced performance occurred. The level of overall responding displayed by Group 11 during Phases 1 and 2 may be taken as the "pure" measure of CC per- 
formance. The mean number of total responses was around 80 . This figure will be used as a frame of reference in considering the level of responding displayed by the various groups under the $C C$ condition.

It is apparent from Figure 6 that Groups 1561, 3311 , and 3161 responded at a much higher level than 80 in Phase 4 . What distinguished these three groups from the others was that they did not experience lack of control with the lever present in both States 1 and 3 or with the lever absent in both States 1 and 3 (see Table 2). Unfortunately, the design of this experiment does not allow any clear inference to be drawn about the effect of the $n(n)$ condition. This condition was not experienced during Phase 1 by any of the Groups. It was experienced only in Phase 3 by Groups 156, 216, 316, and 416, and its effect on the level of responding in Phase 4 seems to be confounded with the previous experimental conditions experienced by the animals. For example, in the case of the groups which experienced $\mathrm{CC}$ or $(\mathrm{n}) \mathrm{n}$ in Phases 1 or 2 (Groups 11, 15, 33, and 31) the effect of $n(n)$ in Phase 3 was apparently enhanced performance in Phase 4. On the other hand, for those groups which experienced $\mathrm{nn}$ in Phases 1 or 2 (Groups 22 and 21), the effect of $n(n)$ in Phase 3 could have led to impaired performance in Phase 4 (see Figure 6). In the case of the remaining two groups, both of which experienced (n)-(n) in Phases 1 or 2 , the effect of $n(n)$ in Phase 3 on Phase 4 performance seems to have been negligible.

Perhaps a more direct way of assessing the effect of the $n(n)$ condition would be to compare the level of $\mathrm{CC}$ responding before and after it was experienced. This comparison is possible for Groups 2161,3161, and 4161, each of which received $\mathrm{CC}$ in Phase 2 followed by $\mathrm{n}(\mathrm{n})$ in Phase 3, followed by $C C$, again, in Phase 4 . For Group 2161, the level of responding showed a decline between Phases 2 and 4; for Group 3161, the level of responding showed an increase; and for Group 4161; the level of responding remained fairly constant.

\section{Effect of Initial Experience of Full Control}

It had been thought that initial experience of full control might have an "immunizing" effect which would minimize the consequences of subsequent loss of control; however, there was no evidence to support this supposition. Comparison of Groups 1121 and 2211 in Phase 4 reveals an almost identical level of performance, despite the fact that Group 1121 experienced full control in Phases 1 and 2 whereas Group 2211 experienced lack of control. Whether an immunizing effect would have been apparent in the case of the lack of control condition which produced the greatest impairment, $(n)-(n)$, remains to be seen.

\section{Prolonged vs. Short Exposure to Lack of Control}

Comparison of some of the groups under $\mathrm{CC}$ in Phases 2 and 3 bears on the question of whether extended experience of a particular no-control condition leads to a greater effect than limited experience. The three relevant comparison, which pertain to the $\mathrm{nn},(\mathrm{n}) \mathrm{n}$, and $(\mathrm{n})-(\mathrm{n})$ conditions, respectively, are as follows: Group 221 vs. Group 21, Group 331 vs. Group 31, and Group 441 vs. Group 41. From Figures 5 and 6, it appears that extended experience of $n n$ had no effect, but extended experience of $(n) n$ and of $(n)-(n)$ both led to magnified effects.

\section{Proportion of Sound Opportunities Taken Up}

There was found to be a high correlation between this ratio and total responding, which clearly validates its use. Moreover, in Phase 2, this measure revealed a significant difference between the $\mathrm{CC}$ conditions which was not apparent from the analyses of response levels.

\section{Summary of Findings}

Because of the complexity of the results obtained in this experiment, a summary of the main findings will be given.

(1) Sensory changes which were response-produced resulted in higher levels of responding than noncontingent sensory changes.

(2) Initial experience of lack of control enhanced or impaired subsequent performance when full control was achieved, depending on whether the opportunity to barpress was available. Absence of the lever in State 1 combined with presence of the lever in State 3, (n)n, led to enhanced performance, whereas absence of the lever in both states, (n)-(n), led to impaired performance. On the other hand, presence of the lever in both states, $\mathrm{nn}$, seems to have produced a very slight impairment in performance.

(3) Initial experience in full control did not have an "immunizing" effect against the subsequent experience of lack of control in the case where the lack of control was experienced with the lever present in both states, $\mathrm{nn}$.

(4) Amount of experience of lack of control proved to be of importance with respect to the $(n) n$ and the (n)-(n) conditions but not with respect to the nn condition.

(5) The proportion of sound opportunities exploited (State 3/State 1 responses) was highly correlated with the overall level of responding and, on occasion, revealed differences between groups which were not detected by total responding, State 1 responding, or State 3 responding.

\section{EXPERIMENT 3}

In this study, the effects of withdrawal of control 
were systematically studied in a situation where all subjects initially experienced full control. In the final phase of the experiment, full control was regained by all subjects. A retractable lever was used, as in Experiment 2.

\section{Subjects \\ Method \\ The subjects were 88 naive female hooded Wistar rats, approxi- mately 120 days of age at the start of the experiment. They were maintained under the same conditions as the subjects in Experi- ments 1 and 2.}

\section{Apparatus}

The apparatus was identical to that used in Experiments 1 and 2 .

\section{Procedure and Experimental Design}

The experiment involved repeated testing with a 20 -min session and a 48-h intersession interval. The study was conducted in three phases, summarized in Table 3.

Phase 1. All 88 rats received the same treatment in Phase 1, namely 1220 -min sessions of $C C$.

Phase 2. Following phase 1 , rats were allocated to the eight treatment conditions shown in Table 3 . The eight groups were matched with respect to the total level of responding over the last four sessions of Phase 1. The eight treatments shown in Table 3 above represent all combinations of the three possible conditions for States 1 and 3 except for the combination (n) (n). This condition was omitted because it would have permitted no responding. Subjects in Group 1 retained control over both light and sound changes, subjects in Groups 2 and 3 retained control over light changes but lost control over sound changes, subjects in Groups 4 and 5 lost control over light changes but retained control over sound changes, and subjects in Groups 6-8 lost control over both light and sound changes.

All subjects were given 12 20-min sessions of Phase 2 training and were then transferred to Phase 3.

Phase 3. In Phase 3, all subjects reverted to the full-control condition, $\mathrm{CC}$, for six 20 -min sessions.

\section{Performance Measures}

the number of barpresses emitted during Phases 1 and 3, the number of barpresses made during the first $2.5 \mathrm{sec}$ of State 1 , response latencies in State 3, and the number of responses made during each 5 -min quarter of each 20 -min session were recorded.

\section{Results}

The acquisition curves during Phase 1 , shown in Figure 7, were similar to those obtained for the $\mathrm{CC}$

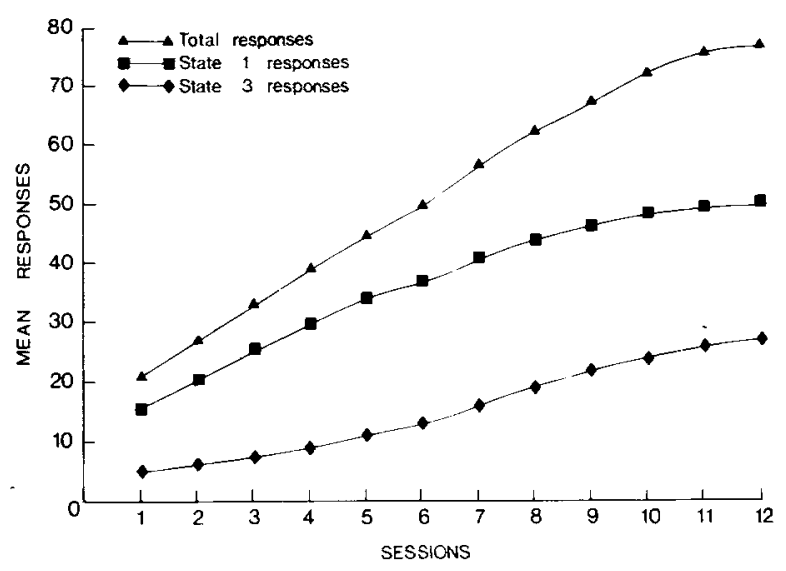

Figure 7. Experiment 3 Phase 1, fitted acquisition curves.

group in Experiment 2 (see Figure 3), showing a clear increase over sessions.

\section{Phase 2}

The acquisition curves during Phase 2 for State 1 and State 3 responses are shown in Figures $8 a$ and $8 \mathrm{~b}$, respectively. The two groups for which responding was not possible, Groups 4 and 6 , in the former case, and Groups 2 and 7 , in the latter case, are not represented.

Some of the groups showed a steady increase or decrease in State 1 responding, as is shown in Figure 8a. The only clear increases were shown by Group 1, CC, and Group 3, Cn, and the only clear decreases were shown by Group $7, n(n)$, and Group 8, nn. The other group which retained control of light onset, Group 2, C(n), maintained a lower level of State 1 responding than Groups 1 and 3 and, if anything, displayed a slight decrease over sessions. Group 5, nC, produced an immediate drop from the level of responding in Phase 1, but showed no decline over sessions during Phase 2 and exhibited a much higher level of State 1 responding than the other two groups which lost control of light onset (Groups 7 and 8).

Comparison of Figure $8 \mathrm{~b}$ with Figure 7 shows

Table 3

Experiment 3: Summary of Experimental Conditions in Each Phase

\begin{tabular}{ccll}
\hline $\begin{array}{c}\text { Treatment } \\
\text { (Group) }\end{array}$ & Abbreviation & \multicolumn{1}{c}{ Light } & \multicolumn{1}{c}{ Sescription } \\
\hline 1 & $\mathrm{CC}$ & Contingent & Contingent \\
2 & $\mathrm{C}(\mathrm{n})$ & Contingent & Noncontingent (lever OUT) \\
3 & $\mathrm{Cn}$ & Contingent & Noncontingent (lever IN) \\
4 & $\mathrm{(n)C}$ & Noncontingent (lever OUT) & Contingent \\
5 & $\mathrm{nC}$ & Noncontingent (lever IN) & Contingent \\
6 & $(\mathrm{n}) \mathrm{n}$ & Noncontingent (lever OUT) & Noncontingent (lever IN) \\
7 & $\mathrm{n}(\mathrm{n})$ & Noncontingent (lever IN) & Noncontingent (lever OUT) \\
8 & $\mathrm{nn}$ & Noncontingent (lever IN) \\
\hline
\end{tabular}

Note-The eight treatments were those received by the eight groups in Phase 2. In Phases 1 and 3, all groups received treatment CC. 

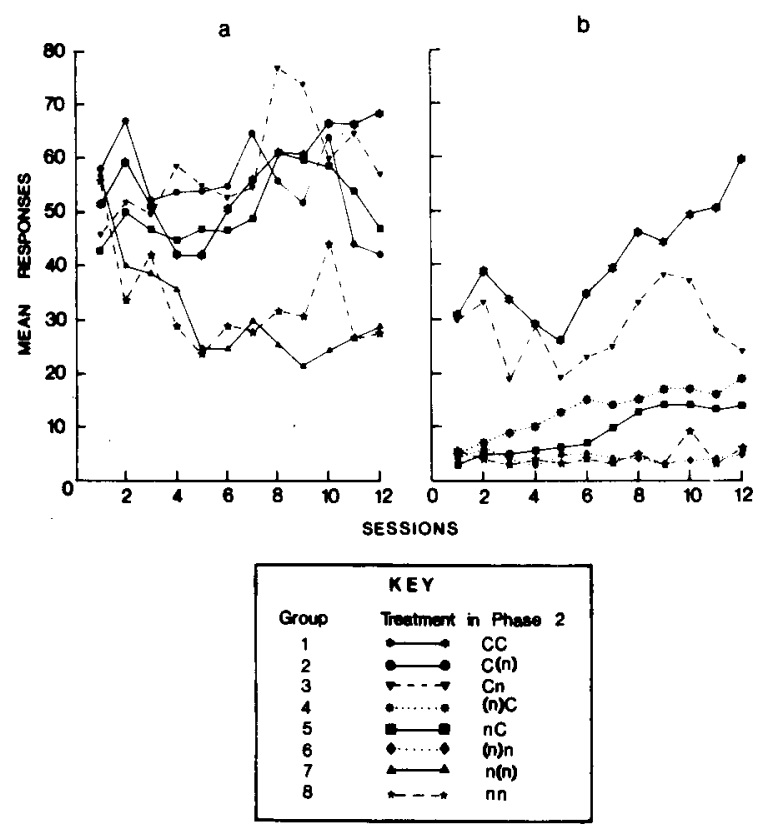

Figure 8. Experiment 3 Phase 2, fitted acquisition curves: (a) State 1 responses, (b) State 3 responses. that the four groups which lost control of light onset, Groups 4, 5, 6, and 8, all showed an immediate and marked drop in State 3 responding. However, the two groups which retained control over sound offset, Groups 4 and 5, both showed a steady increase in State 3 responding throughout Phase 2, whereas the two groups which also lost control over sound offset, Groups 6 and 8, showed no change in State 3 responding.

Of the two groups which retained control over light onset, Group 1, CC, which also retained control over sound offset, showed a steady increase in State 3 responding, whereas Group 3, Cn, which lost control over sound offset, showed no change in State 3 responding.

Mean responses over the terminal four sessions of Phase 2 are shown in Figure 9.

Figure 9 also illustrates the very high level of efficiency achieved by Group 1 in terms of the proportion of sound change opportunities which were taken up. By the end of Phase 2, this group was exploiting more than $80 \%$ of its opportunities, whereas at the end of Phase 1 the overall level was only around $50 \%$.

Two-way analyses of variance on State 1 and State 3

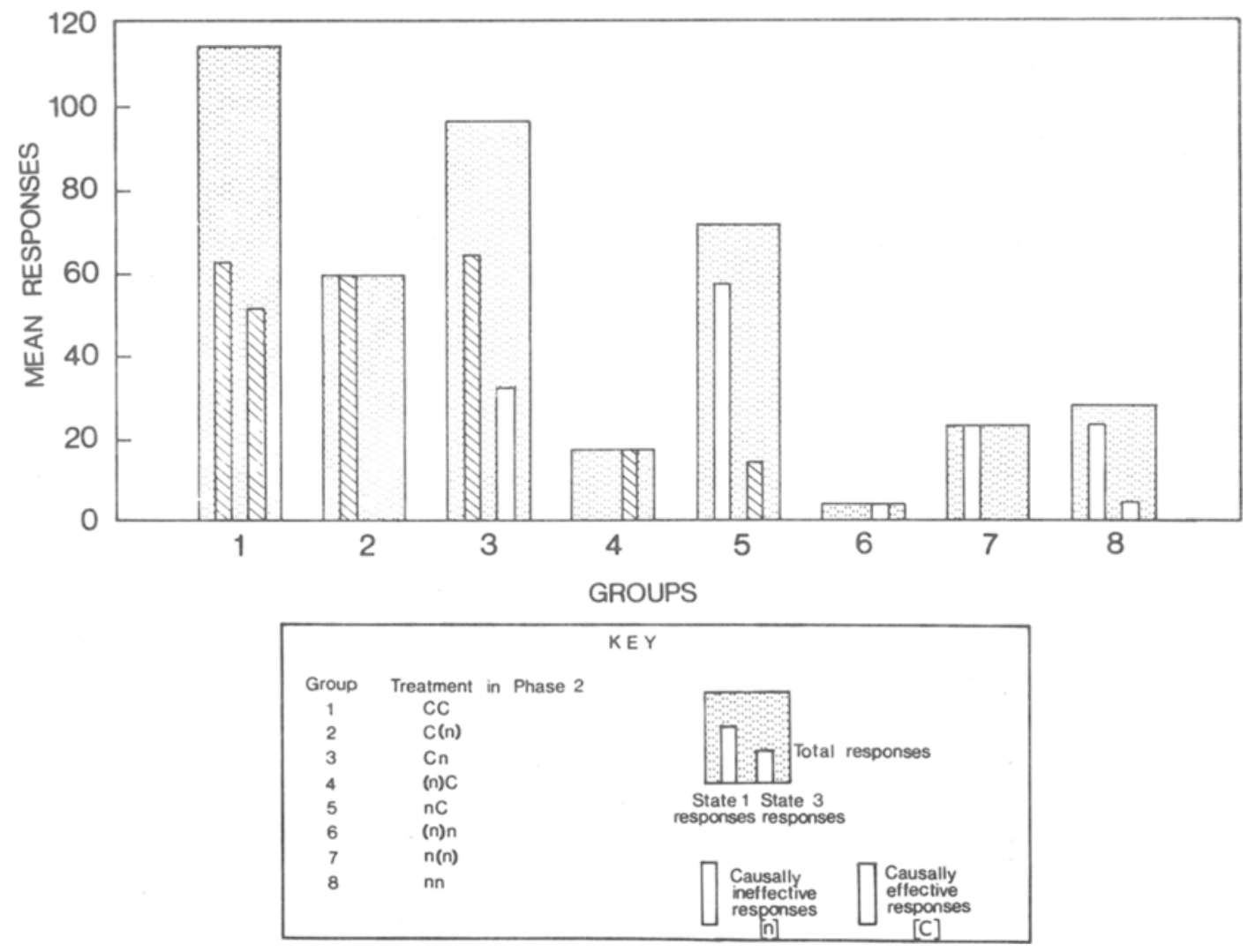

Figure 9. Experiment 3 Phase 2, mean responses over last four sessions. 
responding were carried out over the last four sessions of Phase 2. In each case, this involved disregarding the two groups for which responding was not possible, Groups 4 and 6 in the former case and Groups 2 and 7 in the latter. It should be noted that although this procedure resulted in cell frequencies which were unequal, they were nevertheless proportional (cf. Winer, 1971, p. 420), so that variations due to main effects and interaction were additive. The analysis of State 1 responding showed a significant effect for light control $[F(1,62)=10.74, p<$ $.01]$, a significant effect for sound control $[F(1,62)$ $=6.11, \mathrm{p}<.025]$, and an insignificant interaction effect $[F(1,62)=1.61, p>.05]$.

It is clear from Figure 9 that State 1 responding will be maintained, provided it controls light onset, regardless of whether sound control is retained. However, if light control is lost, State 1 responding may still continue at a high level provided sound control is not also lost. If sound control is lost, the presence or absence of the lever in State 3 appears to have no effect on the level of State 1 responding.

By contrast, the level of State 3 responding was strongly influenced by whether or not light control was retained. A two-way analysis of variance on State 3 responding over the terminal four sessions of Phase 2 showed a significant effect for light control $[F(1,62)=40.3, p<.001]$, a significant effect for sound control $[F(1,62)=25.5, p<.001]$, and an insignificant interaction effect $[F(1,62)<1]$.

From Figure 9, it can be seen that State 3 responding was higher for Group 3, which lost sound control but retained light control, than for Groups 4 and 5 , both of which retained and sound control but lost light control.

\section{Phase 3}

Figure 10 shows the mean number of responses over the six sessions of Phase 3 (there was little change over sessions for any of the groups).

An analysis of variance on State 1 responses gave an $F(7,80)=2.40, p<.025$. Post hoc comparisons showed that the differences between Group 4 and Groups 5, 6, 7, and 8 were all significant at the $5 \%$ level. For State 3 responding, $F(7,80)=2.23, p<$ .05 . Post hoc comparisons showed that Group 4 differed significantly from all of the others, with the exception of Group 1.

\section{Proportion of Sound Change Opportunities Taken Up}

The ratio of State 3/State 1 responses measures behavioral efficiency in the sense of the proportion of opportunities to control sound which are actually taken up. Again, the value of this ratio can be seen by comparing the two bar heights for each group in Figure 10. Apparently, Groups 4 and 5 were the most efficient, taking up about $80 \%$ of their oppor- tunities, whereas Groups 2 and 3 were the least efficient, taking up only about $50 \%$ of their opportunities.

An analysis of variance on the State 3/State 1 response ratios using the $2 \arcsin \sqrt{x}$ transformation yielded an $F(7,80)=3.83$, p $<.01$. Post hoc comparisons showed that both Group 4 and Group 5 differed significantly from each of Groups 2, 3, 6, and 8 and that Group 1 differed significantly from Group 3.

\section{Other Response Measures}

In all three phases of the experiment, various response measures were recorded which have not been described. For example, response latencies, response rates over the four quarters of each session, and the number of State 1 responses occurring within $2.5 \mathrm{sec}$ were all recorded. The latter measurement was important because it allowed a direct comparison of State 1 and State 3 response levels. In fact, two of these measures failed to produce interesting data, insofar as response latencies were related to response rates, and there was little variation of response rates within sessions. On the other hand, State 1 responses occurring within $2.5 \mathrm{sec}$ were reliably fewer than the number of State 3 responses showing that animals were responsive to the time constraint operating in State 3.

All groups in both Phase 1 and Phase 3 produced significantly more responses in State 3 than in the first $2.5 \mathrm{sec}$ of State 1. The Phase 2 data for those groups which had access to the lever in both states (Groups 1, 3, 5, and 8) were analyzed. All of these produced more responses in State 3, and the differences were significant except for Group 8.

\section{Discussion}

The experiment reported here was concerned with two general questions: the effect on ongoing barpressing behavior of losing control over sensory change, and the subsequent effect when full control is regained. Phase 2 of the experiment was concerned with the first question and Phase 3 with the second.

So far as loss of control is concerned, in general the level of barpressing was depressed, the extent depending on the extent of the loss of control. With complete loss of control (Groups 6, 7, and 8), the level of State 1 barpressing dropped gradually during Phase 2, and the level of State 3 barpressing dropped immediately in Phase 2. With partial loss of control (Groups 2, 3, 4, and 5), the effects were more complex. For Groups 2 and 3, which lost control only over sound change, the availability of the lever in State 3 seemed to affect the level of State 1 responding. Group 3, for which the lever was present in State 3, maintained a higher level of State 1 responding than Group 2, for which it was absent. For Groups 4 and 5, which lost control over light change 

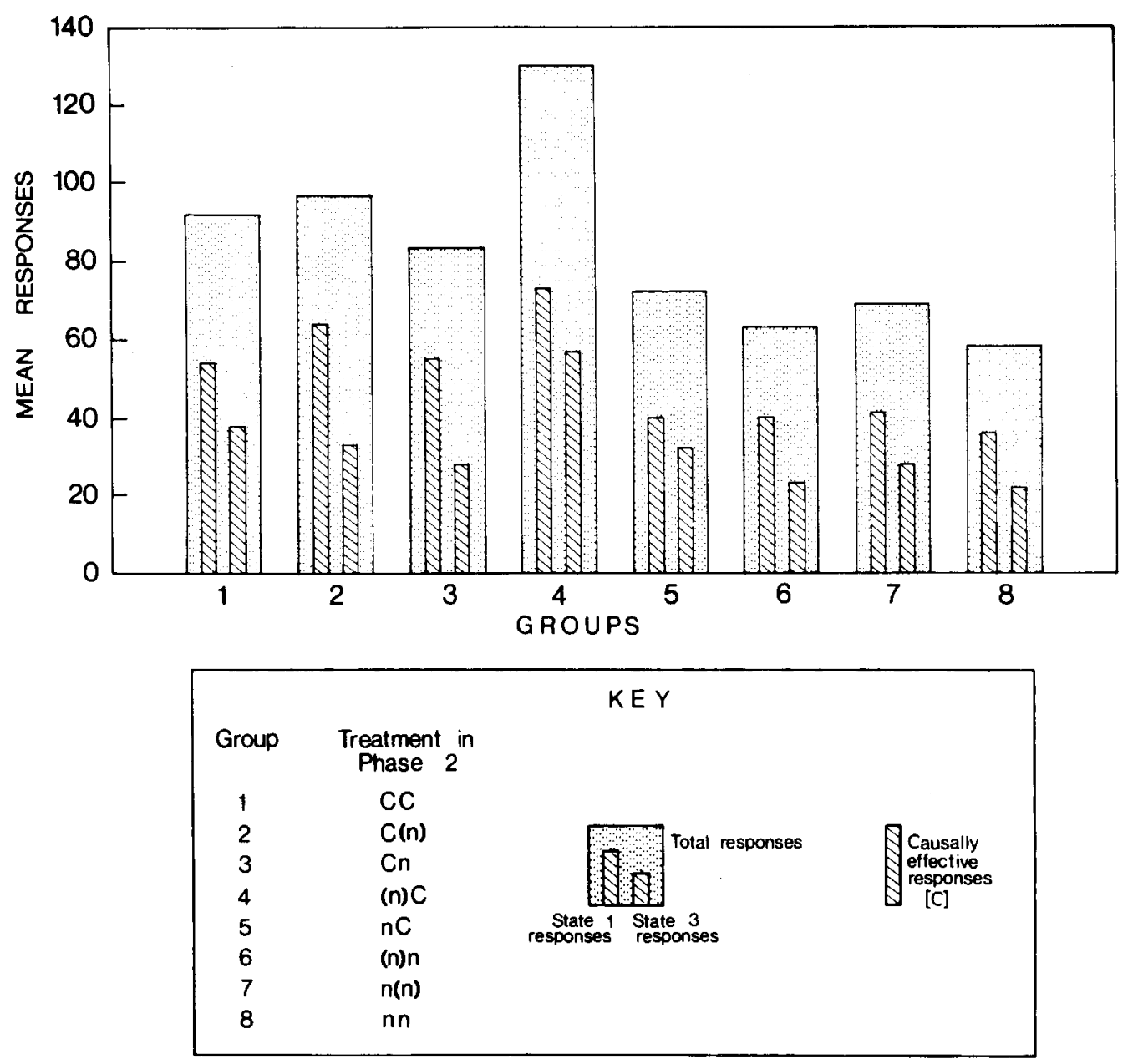

Figure 10. Experiment 3 Phase 3, mean responses.

but retained control over sound change, the level of State 3 responding dropped immediately but gradually increased over sessions. Paradoxically, the level of State 1 responding for Group 5 did not decline, despite the fact that light changes were no longer contingent. For this group, it seems that the retained control over sound change led to State 1 responding continuing at a high level, although State 3 responding showed a decline. A probable explanation for this last finding is that State 3 responding is highly dependent on predictable light change. A State 3 response is restricted to the last $2.5 \mathrm{sec}$ of a $3-\mathrm{sec}$ light change. Unless a subject has control over light change, it would be unable to predict its occurrence. Moreover, when the light change is responsecontingent, it must necessarily occur when the subject is positioned in the vicinity of the lever (having just pressed it). This would also explain why the level of State 3 responding was found to be higher when light control was retained. It also explains the increase in State 3 responding for Groups 4 and 5 following the initial withdrawal of light control. Subjects in these groups evidently learned to adjust to the new situation in which light changes were no longer predictable. By the end of Phase 2, their State 3 responding had reached a much higher level than that of Groups 6 and 8, which lost sound control as well as light control.

The effects of loss of control (complete or partial) within the $\mathrm{CC}$ paradigm are reasonably clear-cut, but nonetheless complex. They can be summarized as follows:

(1) Complete loss of control. This resulted in a gradual reduction in State 1 and an immediate reduction in State 3 responding.

(2) Partial loss of control. (a) Loss of light control only. This produced a small and very gradual reduction in State 1 responding and a large, immediate drop in State 3 responding, followed by a gradual increase. (b) Loss of sound control only. State 1 responding was unaffected provided the lever remained available during State 3, otherwise State 1 responding showed a small, gradual decline. State 3 responding declined, but to a lesser extent than occurred under the other conditions where control was reduced or withdrawn. 
It should be borne in mind that the propositions contained in the above summary are all made with respect to the levels of State 1 and State 3 responding displayed by Group 1, CC. Because this group retained full control throughout Phase 2 , it can be regarded as the "control group," against which the behavior of the other "experimental groups" can be compared. Figure 8 shows that Group 1 increased its levels of both State 1 and State 3 responding in Phase 2 . Consequently a group which merely maintained the same level of responding (e.g., State 3 responding by Group 3) would have shown a relative decline.

The second question with which this study was concerned was the effect of complete and partial loss of control on behavior when full control was regained. This was looked at in Phase 3 of the experiment. For seven of the eight groups, the level of responding for both State 1 and State 3 responses showed little change during Phase 2. Only Group 7 $\mathrm{n}(\mathrm{n})$, showed a steady increase in both responses on regaining full control.

From Figure 10, it seems that withdrawal of light control produced a depressed level of State 1 responding even after full control was regained-with one significant exception. Group 4, (n)C, exhibited the highest level of State 1 responding, whereas in the case of the other seven groups those which had retained light control, Groups 1, 2, and 3, produced more State 1 responses than those which had lost it, Groups 5, 6, 7, and 8 .

The absolute level of State 3 responding is not the best measure in the CC condition because State 3 responses depend on State 1 responses. Because of this, the ratio of State 3 to State 1 responses is likely to be a more meaningful indicator of performance than State 3 responses per se. This ratio is perhaps best seen as a measure of behavioral efficiency, the proportion of opportunities to produce a sound change which are actually utilized.

Treating Group 1, which retained full control throughout the experiment, as the "frame of reference," Figure 10 shows that State 1 responding was apparently enhanced by the loss of control experienced by Group 4, unaffected by the loss of control experienced by Groups 2 and 3, and depressed by the loss of control experienced by Groups 5, 6, 7, and 8. This result is somewhat puzzling, because Group 4 was the only group experiencing loss of light control whose level of State 1 responding was not subsequently depressed. This apparently anomalous result can be attributed to the difference between withdrawal of control with the lever absent and with the lever present. Where the lever is withdrawn, the opportunity for control is lost, whereas when the lever remains, the opportunity for control is still there, but responding is no longer effective. It is possible, then, that the notion of "learned ineffectiveness" might be applied to those cases where the lever remains but where sensory change is no longer contingent on responding. Certainly, the overall level of responding in Phase 3 was only depressed for those groups which had experienced an ineffective lever. Groups 2 and 4, for which loss of control only implied nonavailability of the lever, produced as many responses as Group 1.

Of course, the learned ineffectiveness hypothesis would not account for the enhanced State 1 responding shown by Groups 2 and 4, particularly the latter. This behavior seems to be explicable in terms of frustration theory (Amsel, 1967). Indeed, it might have been supposed that all of the operations involving loss of control would be frustrating, and consequently lead to increased levels of responding. No such results were observed during Phase 2 when control was withdrawn, because Group 1, which retained control, maintained higher levels of both State 1 and State 3 responding than any of the other groups. It appears, then, that a delayed frustration effect has occurred in those cases where loss of control entailed loss of opportunity for control (as opposed to ineffective responding). The hypothetical frustration effect manifested itself by an increased rate of responding when full control was regained.

The levels of State 1 responding which were observed in Phase 3 seem to be neatly explained either in terms of learned ineffectiveness or in terms of a frustration effect. Perhaps the State 3 responses in Phase 3 can be explained in similar terms.

As has been stated, under the light control condition, the absolute number of State 3 responses is not a meaningful measure because of the dependence on State 1 responses; therefore the State 3/State 1 ratio will be taken as the more appropriate measure. On this measure, Group 1 scored $61 \%$, which can be taken as a standard. By comparison, Groups 4 and 5 showed an increase in efficiency by taking up $70 \%$ and $72 \%$ of their opportunities, respectively. Groups 6 and 8 showed a decrease in efficiency, taking up $44 \%$ and $48 \%$ of their opportunities, respectively, and Groups 2 and 3 both showed a decrease in efficiency, taking up only $44 \%$ and $40 \%$ of their opportunities, respectively. Group 7 took up $58 \%$, about the same as Group 1.

The most obvious explanation for these differences is that the subjects engaged in a "tradeoff." Groups 2 and 3, which retained light control but lost sound control, might have invested less effort in trying to control sound, whereas Groups 4 and 5, which lost light control but retained sound control, might have concentrated more on controlling sound. In other words, there seems to have taken place a shift in preference. It is interesting that the percentage of sound change opportunities taken up is evi- 
dently independent of whether loss of control involved loss of opportunity (lever OUT) or ineffective responding (lever IN).

Overall, this experiment has demonstrated that losing control over sensory change results in reduced responding, the extent of which depends on the amount and nature of the loss of control. When control is regained, responding may be permanently enhanced or depressed, depending on whether the loss of control experienced involved loss of opportunity or loss of effectiveness. Similarly, behavioral efficiency-as measured by the percentage of created opportunities to produce a sound change which are exploited-may be increased or decreased as a result of experiencing different kinds of loss of control. It was suggested that the results could be interpreted in terms of learned ineffectiveness, frustration, and preference shift.

\section{CONCLUSIONS}

The general hypothesis advanced in this paper is that response-produced sensory change is reinforcing, not simply because of stimulus change or because some sensory states are preferred to others, but because information about, and control over, the environment have motivational and reinforcing properties.

The CC paradigm, under some experimental conditions, gave rise to much higher levels of responding than is usually reported in studies of sensory reinforcement. For example, in Experiments 2 and 3, some groups averaged 120 or more responses $/ 20$-min session, yielding a mean response rate of $6 / \mathrm{min}$, whereas sensory reinforcement studies with a one-toone relationship between a piece of behavior and an environmental change typically find levels of responding of around 25-30 responses/20-min session (Glow \& Russell, 1974a).

The main research strategy followed was to study the effects of varying the kind and amount of control over the sensory environment on subsequent behavior when full control was given. On the basis of the findings obtained, the following propositions are advanced:

(1) Causally effective responding is maintained at a level that is significantly higher than responding that is causally ineffective, and is higher in a causally structured than in a causally unstructured environment.

(2) Rats are able to recognize and respond to temporal constraints in a causally structured environment.

(3) Initial experience of lack of control may have lasting effects on behavior when full control is achieved, either by depressing or by enhancing performance, depending on the nature of the lack of control.
(4) Reduced control which involves ineffective responding tends to disrupt subsequent performance (learned ineffectiveness), whereas reduced control which involves lack of opportunity to respond may enhance subsequent performance, and both may affect animal's preferences for one sensory change over another.

(5) Initial experience of full control sensitizes animals to subsequent loss of control so that its effect on subsequent performance when full control is regained are magnified.

The results obtained so far have been very encouraging and fully justify further investigations of the CC paradigm. It is doubtful whether similar findings could have been obtained using conventional reinforcers, such as food or shock. Because of their powerful effects on behavior, almost certainly the numerous subtle effects which occur with weaker, sensory reinforcers would be obscured.

An important question which has so far not been resolved is whether control and predictable sensory change are both independently reinforcing. These variables are not easy to separate because control normally produces predictable change. We suggest that both should have motivational and reinforcing properties, but the experiments reported here have not demonstrated this. What they have shown is that control which produces predictable changes has motivational and reinforcing properties.

Various other questions arise from our work. For example, assuming that rats prefer some sensory changes to others, is it possible that such preferences are not wholly determined by the sensory states that the changes produce? Will rats respond in order to preserve the status quo as well as to produce a sensory change and will they withhold a response in order to produce (or prevent) a sensory change?

\section{REFERENCES}

Amset, A. Partial reinforcement effects on vigor and persistance: Advances in frustration theory derived from a variety of within-subjects experiments. In K. W. Spence \& J. T. Spence (Eds.), The psychology of learning and motivation (Vol. 1). New York: Academic Press, 1967. Pp. 1-65.

BERLYNE, D. E. The reward-value of indifferent stimulation. In J. T. Tapp \& G. W. Meier (Eds.), Reinforcement. New York: Academic Press, 1969.

Duncan, D. B. Multiple range and multiple F tests. Biometrics, 1955, 11, 1-42.

Glow, P. H., Roberts, J. E., \& Russell, A. Sound and light preference behaviour in naive adult rats. Australian Journal of Psychology, 1972, 24, 173-178.

Glow, P. H., \& Russell, A. A period of time-out from flickering light as a sensory reinforcer. Australian Journal of Psychology, 1972, 24, 107-112.

Glow, P. H., \& Russell, A. Sensory-contingent bar pressing for familiar and novel change under a dexamphetamineamylobarbitone mixture. Animal Learning \& Behavior, 1974, 2, 27-30. (a)

Glow, P. H., \& Russell, A. Sensory contingent bar pressing for various combinations of sensory change: The effect of 
reinforcement variability. Australian Journal of Psychology, 1974, 26, 25-29. (b)

Glow, P. H., Russell, A., \& Duckmanton, R. A. Successive discrimination in the rat using sensory change as the reward. Australian Journal of Psychology, 1973, 25, 131-137.

Hiroto, D. S. Locus of control and learned helplessness. Journal of Experimental Psychology, 1974, 102, 187-193.

Hulse, S. H. Patterned reinforcement. In G. H. Bower (Ed.), The psychology of learning and motivation (Vol. 7). New York: Academic Press, 1973. Pp. 313-362.

Kavanau. J. L. Behavior of captive white-footed mice. Science, $1967,155,1623-1639$.

Kelleher, R. T. Chaining and conditioned reinforcement. In W. K. Honig (Ed.), Operant behavior: Areas of research and application. New York: Appleton-Century-Crofts, 1966. Pp. 160-212.

KIsH, G. B. Studies of sensory reinforcement. In W. K. Honig (Ed.), Operant behavior: Areas of research and application. New York: Appleton-Century-Crofts, 1966. Pp. 109-159.

LEFCOURT, H. M. Internal versus external control of reinforcement revisited: Recent development. In B. A. Maher (Ed.), Progress in experimental personality research (Vol.6). New York: Academic Press, 1972.

LockARD, R. B. Several tests of stimulus change and preference theory in relation to light-controlled behavior of rats. Journal of Comparative and Physiological Psychology, 1966, 62, 415-426.

Maier, S. F., \& Seligman, M. E. P. Learned helplessness: Theory and evidence. Journal of Experimental Psychology, General, 1976, 105, 3-46.

RotTER, J. B. Generalized expectancies of internal versus external control of reinforcement. Psychological Monographs, 1966, 80(1. Whole No. 609).

Seligman, M. E. P. Helplessness. San Francisco: Freeman, 1975. WhITE, R. W. Motivation reconsidered: The concept of competence. Psychological Review, 1959, 66, 297-333.

WINER, B. J. Statistical principles in experimental design. New York: McGraw-Hill, 1971.

\section{NOTE}

1. All post hoc tests reported in this paper are based on the statistic.

(Received for publication February 10, 1977; revision accepted September $25,1977$. 